Research Article

\title{
Observational study to assess prescription cost and its relation to the socioeconomic status of the patients in psychiatry outpatient department in a tertiary care hospital
}

\author{
Sumit G. Goyal, Dnyaneshwar G. Kurle*, Balwant D. Samant
}

\begin{abstract}
Department of Pharmacology \& Therapeutics, Seth GS Medical College \& KEM Hospital, Parel, Mumbai 400012, India
\end{abstract}

Received: 13 March 2016

Accepted: 16 March 2016

*Correspondence to:

Dr. Dnyaneshwar G. Kurle, Email:dgkurle@yahoo.com

Copyright: (C) the author(s), publisher and licensee Medip Academy. This is an openaccess article distributed under the terms of the Creative Commons Attribution NonCommercial License, which permits unrestricted noncommercial use, distribution, and reproduction in any medium, provided the original work is properly cited.

\section{ABSTRACT}

Background: To analyse the cost of prescriptions and to determine the relationship between socioeconomic status of the patients and the cost of prescriptions.

Methods: A prospective, observational study was conducted in psychiatry OPD of a tertiary care hospital from August 2007 to January 2008. 300 patients of either sex and irrespective of age suffering from mental disorders were included. Information about the socioeconomic status of the patient was analysed on the basis of Kuppuswami's socioeconomic status scale (updated for 2007). Cost analysis (calculated for 30 days) was done by calculating (a) average cost of the prescription borne by the hospital (b) average cost of the prescription borne by the patient and (c) average total cost of the prescription. The correlation between the socioeconomic score of the patients with the above three cost parameters was carried out using the Spearman rank correlation.

Results: In a cohort of 300 patients, $61.3 \%$ patients belong to upper lower class. Cost analysis showed that the average total cost of the prescription was 121.97 INR of which average cost of the prescription borne by the hospital and the patients was 18.43 INR and 103.54 INR respectively. The total cost of the prescription and cost of prescription borne by the patient had a positive correlation with the socioeconomic score of the patient, while the cost of prescription borne by the hospital was inversely correlated with the socioeconomic score of the patient.

Conclusions: It seems that the prescribing decision was influenced by the socioeconomic status of the patients.

Keywords: Drug Costs, Psychiatry, Tertiary healthcare, Socioeconomic status

\section{INTRODUCTION}

World Health Organization (WHO) in the World Health Report 2001 states that more than $25 \%$ of all population in the world at some time during their lives are affected by mental and behavioural disorders. These disorders, which accounted for $12 \%$ of the total disability adjusted life years (DALYs) lost due to all diseases and injuries in 2000 , are projected to increase to $15 \%$ in $2020 .{ }^{1}$ Mental disorders not only have an adverse effect on the quality of life of the patients but also have a negative economic impact on societies. Unfortunately, mental disorders are not given the same importance as physical health in most parts of the world. Instead, they have been largely neglected especially in the developing countries such as India.
The prescriptions for drugs for mental disorders are increasing in different parts of the world..$^{2-4}$ Data from the prescription cost analysis 1998-2010 in England showed that prescriptions for antidepressants and antipsychotics were increased by $10 \%$ and $5.1 \%$ per year respectively. ${ }^{2}$ Prescription behaviour of physicians of the respective countries is affected by a variety of factors such as health care system, financing schemes, medical traditions, availability of the drugs, cost of the drugs and the overall socio cultural background. ${ }^{5}$ Cost of the drugs accounts for $10-15 \%$ and up to $30-40 \%$ of the total cost of health care in the developed countries and developing countries respectively. ${ }^{6}$ Cost of the drugs and affordability of the patients remain a significant consideration for a physician, who is prescribing drugs for mental disorders. Although mental disorders are associated with high levels 
of health service utilization in both developed and developing countries, the associated costs of treatment are mostly paid by the patients without any support from the Government in the developing countries. Further, the introduction of newer and expensive drugs for mental disorders may be found to increase the drug expenditure for patients with mental disorders.

The focus of health care policy of the respective countries is to provide quality health care within the available financial resources. Health care policy makers are now increasingly dependent on clinical economic data to guide policy formulations and implementations. Additionally, data on cost of drugs is important to ensure that physicians are prescribing affordable drugs, which are within the means of the patients. Although drug utilization studies to find out prescription patterns for the treatment of mental disorders have appeared in medical literature, less work has been carried out in India on economic burden and its impact on patients with mental disorders. ${ }^{71}$ In India, most of the patients coming to the tertiary care hospital belong to lower socioeconomic status. It may be expected that the cost of the prescription is related to socioeconomic status of the patient. Unfortunately, there is no published research data to support this proposition. Therefore the present study was carried out in the psychiatric outpatient department (OPD) in our tertiary care hospital in order to analyse the cost of prescriptions and to determine the relationship between socioeconomic status of the patients and the cost of prescriptions.

\section{METHODS}

A prospective, observational study was conducted in the psychiatry OPD of a tertiary care teaching hospital for a period of 6 months from August 2007 to January 2008. The protocol of the study was approved from the Institutional Ethics Committee (IEC) before initiating the study. 300 patients suffering from three classes of mental disorders (Schizophrenia \& other psychotic disorders, Mood disorders, Anxiety disorders) of either sex and irrespective of age were included. Diagnosis was given by the psychiatrists based on DSM IV TR criteria. ${ }^{12}$ Written informed consent was obtained from the patients or his/her relative after complete explanation of the study. Information about the socioeconomic status of the patient was obtained and analysed on the basis of Kuppuswami's socioeconomic status scale (updated for 2007). ${ }^{13}$

\section{Parameters evaluated}

Cost analysis (calculated for 30 days) was done by calculating (a) average cost of the prescription borne by the hospital (b) average cost of the prescription borne by the patient and (c) average total cost of the prescription. The cost of prescription borne by the hospital was calculated on the basis of price list available in hospital pharmacy. 14 drugs were available in the hospital pharmacy for the treatment of three classes of mental disorders (Schizophrenia \& other psychotic disorders, Mood disorders, Anxiety disorders) and these drugs were considered for the calculation of cost of the prescription borne by the hospital (Table 1). The cost of prescribed drugs, which were not available in the hospital pharmacy, was calculated on the basis of price list of a subsidized outside medical store approved by the hospital management. The correlation between the socioeconomic score of the patient with total cost of the prescription, cost of the prescription borne by the hospital and cost of the prescription borne by patient was carried out using the Spearman rank correlation. The data of the study was statistically analysed using SPSS version 15.0 statistical software.

\section{RESULTS}

In a cohort of 300 patients, $61.3 \%$ patients belong to upper lower class as shown in Figure 1. A total of 758 drugs were prescribed of which $511(67.41 \%)$ drugs were prescribed from the drugs that were available in hospital pharmacy.

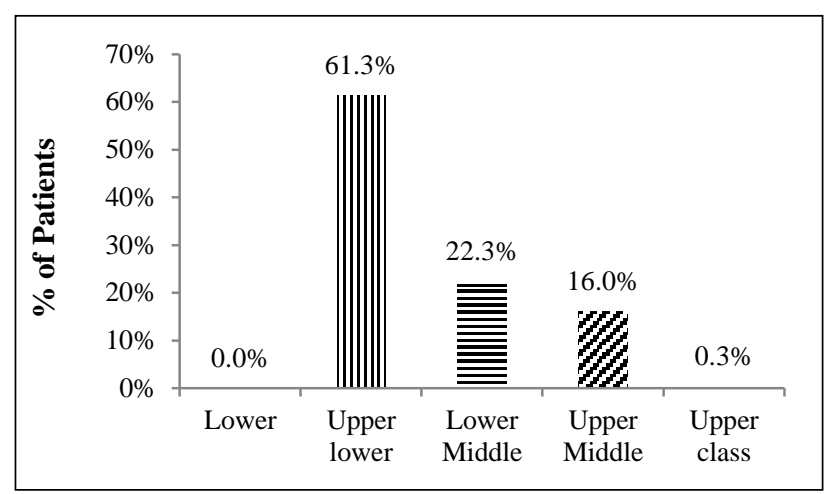

Figure 1: Percentage of patients in different socioeconomic classes. $(n=300)$.

Table 1: List of drugs for mental disorders available in hospital pharmacy.

\begin{tabular}{|lll|}
\hline $\begin{array}{ll}\text { Sr. } \\
\text { No. }\end{array}$ & Name of the drug & Formulation available \\
\hline 1. & Trifluoperazine & Tablet: $5 \mathrm{mg}$ \\
\hline 2. & Chlorpromazine & Tablet: $25 \mathrm{mg} ; 100 \mathrm{mg}$ \\
\hline 3. & Haloperidol & Tablet: $1.5 \mathrm{mg} ; 5 \mathrm{mg}$ \\
\hline 4. & Risperidone & Tablet: $2 \mathrm{mg}$ \\
\hline 5. & Olanzapine & Tablet: $5 \mathrm{mg}$ \\
\hline 6. & Trihexyphenidyl & Tablet: $2 \mathrm{mg}$ \\
\hline 7. & Imipramine & Tablet: $25 \mathrm{mg}$ \\
\hline 8. & Amitriptyline & Tablet: $25 \mathrm{mg}$ \\
\hline 9. & Escitalopram & Tablet: $5 \mathrm{mg}$ \\
\hline 10. & Carbamazepine & Tablet: $200 \mathrm{mg}$ \\
\hline 11. & Sodium valproate & Tablet: $200 \mathrm{mg}$ \\
\hline 12. & Chlordiazepoxide & Tablet: $10 \mathrm{mg}$ \\
\hline 13. & Diazepam & Tablet: $5 \mathrm{mg}$ \\
\hline 14. & Lorazepam & Tablet: $2 \mathrm{mg}$ \\
\hline
\end{tabular}


Cost analysis showed that the average total cost of the prescription was 121.97 INR of which average cost of the prescription borne by the hospital and the patients was 18.43 INR and 103.54 INR respectively. The correlation between socioeconomic score and above mentioned cost parameters is summarized in Table 2. The scatter diagrams between socioeconomic score and various cost parameters are shown in Figures 2A, 2B \& 2C.

Table 2: Correlation analysis between socioeconomic score of the patients and various cost parameters.

\begin{tabular}{|lll|}
\hline Correlation & \multicolumn{2}{l|}{$\begin{array}{l}\text { Socioeconomic score of the } \\
\text { patients }\end{array}$} \\
\hline $\begin{array}{l}\text { Spearman's } \\
\text { Rho }\end{array}$ & $\begin{array}{l}\text { Significance } \\
\text { (2 tailed) }\end{array}$ \\
\hline $\begin{array}{l}\text { Total cost of } \\
\text { prescription }\end{array}$ & 0.388 & $\mathrm{p}<0.001$ \\
\hline $\begin{array}{l}\text { Cost of prescription } \\
\text { borne by the hospital }\end{array}$ & -0.221 & $\mathrm{p}<0.001$ \\
\hline $\begin{array}{l}\text { Cost of prescription } \\
\text { borne by the patient }\end{array}$ & 0.392 & $\mathrm{p}<0.001$ \\
\hline
\end{tabular}

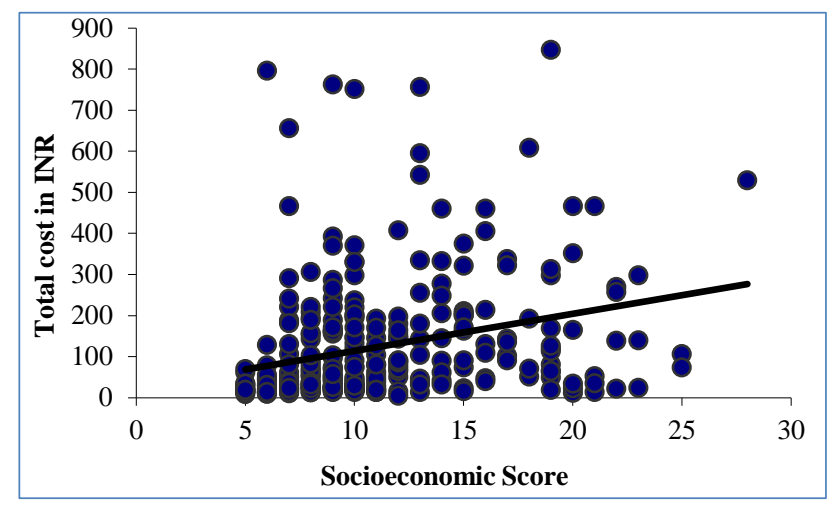

Figure 2A: Scatter plot and best fit line of socioeconomic score versus total cost of prescription (in INR).

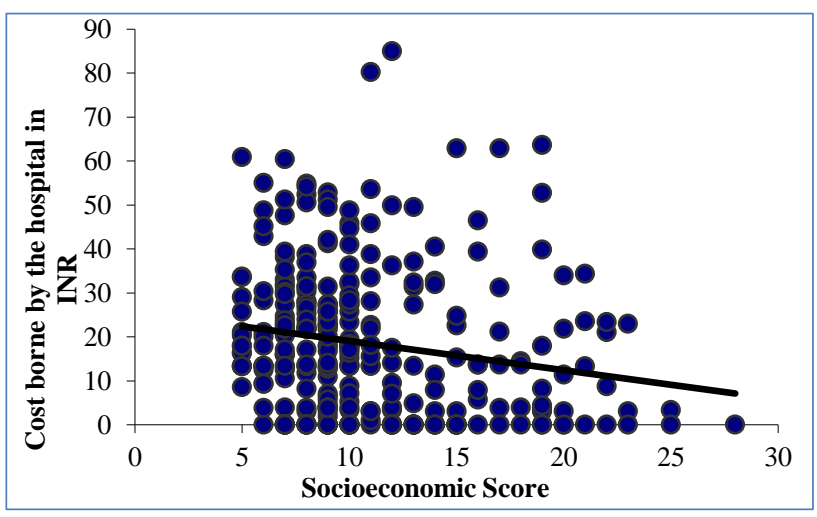

Figure 2B: Scatter plot and best fit line of socioeconomic score versus cost of prescription borne by the hospital (in INR).

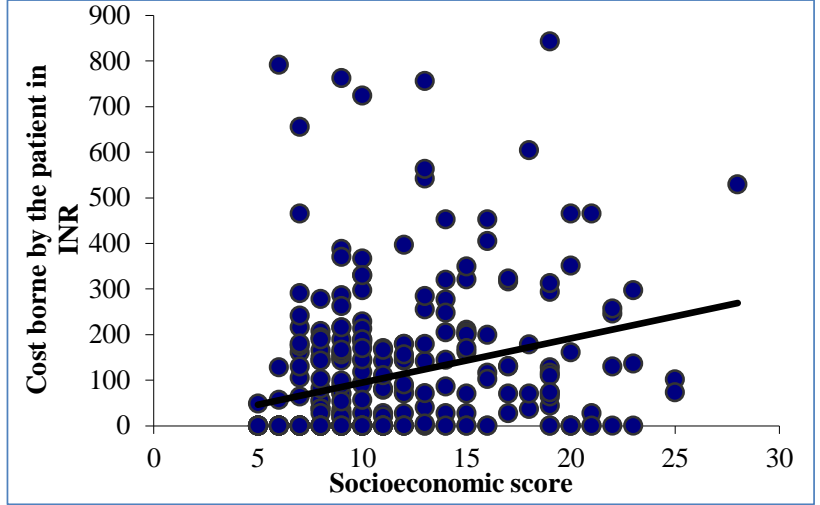

Figure 2C: Scatter plot and best fit line of socioeconomic score versus cost of prescription borne by the patient (in INR).

\section{DISCUSSION}

The cost of drugs in the health care system is the moot point of relevance in the present context. The health care systems have raised concerns about the cost of medical care in general and medication expenditure in particular. Data on cost of drugs is an important consideration for formulating policy related to drug supply, pricing and use. Based on the circumstances and the perspective, estimates of the costs at various levels along with data aggregated in various ways are required. Government perspective might require information on drug costs and cost offsets to government. Societal perspective might require determining both government and private sector costs and cost offsets. However, patient perspective would be more appropriate if affordability and accessibility are being considered to his/her benefits. ${ }^{6}$

The adherence with the medication in mental disorders is found to be lower than physical disorders. In one study, the mean rate of adherence with the medication among patients with physical disorders was $76 \%$ while the mean rate of adherence with the medication among patients with psychoses and depression was $58 \%$ and $65 \%$ respectively. ${ }^{14}$ High medication costs remain one of the main barriers for adherence to medication in patients with chronic diseases such as mental disorders. ${ }^{15,16}$ Non adherence to medication in patients with mental disorders can increase the chances of relapse and longer stay in hospitals resulting increased cost to the patients. ${ }^{17}$ In mental disorders, terms such as direct costs and indirect costs are used when healthcare economics are discussed. Direct costs mainly include fees paid to the doctor, cost of commuting to and from the hospital and cost of medications for mental disorders. Apart from direct treatment costs, cost of absence from work for the patient (if employed) as well as his/her caregiver and value of time in care giving results in indirect costs. All these costs are borne by families as the patient may be unable to work and earn for self. ${ }^{18}$ 
General hospitals cater mainly to patients belonging to lower socioeconomic status. This statement holds true for our hospital also. Majority of patients included in our study were in upper lower socioeconomic class (61.3\%). In our study, average total cost of the prescription for 30 days was 121.97 INR. The average cost of the prescription borne by the hospital for 30 days was 18.43 INR, which was much lesser as compared to average cost of the prescription borne by the patient calculated for 30 days (103.54 INR). Although $67.41 \%$ drugs were prescribed from the hospital pharmacy, the average cost of the prescription borne by patients was 5-6 times more as compared to average cost of the prescription borne by the hospital. Hospital authorities are able to negotiate better and lower prices because they buy medicines in bulk from pharmaceutical companies and their suppliers. Many hospitals purchase generic drugs in comparatively lower rates than existing market prices. Therefore, it is better that hospitals should keep most of the prescribed drugs in their pharmacies in order to reduce the cost burden on the patients.

Although the amount spent by the patients on medications for 1 month was not found to be very high, this cost could not be viewed in isolation. It is not only direct costs but also indirect costs that play a significant role in increasing economic burden on the patients and their caregivers. Patient's adherence to the treatment is primarily dependent on the cost of treatment in a developing country such as India. ${ }^{19}$ This is especially true in mental disorders because of the long duration of treatment. Atypical antipsychotics, selective serotonin reuptake inhibitors (SSRIs), atypical antidepressants and newer benzodiazepines are the examples of relatively expensive drugs, which are prescribed for the treatment of mental disorders, and patient's adherence to the treatment is likely to be poor for such medications.

In this study, the total cost of the prescription was directly correlated with the socioeconomic score of the patient [Spearman's Rho $=0.388, \mathrm{p}<0.001$ ], which indicates that total cost of the prescription increases with the socioeconomic score of the patient. The cost of prescription borne by the hospital was inversely correlated with the socioeconomic score of the patient [Spearman's Rho $=-0.221, \mathrm{p}<0.001]$. This indicates that patients with low socioeconomic status were more dependent to avail medicines from hospital pharmacy and perhaps could not afford to buy the medicines from outside medical store. The cost of prescription borne by the patient had a positive correlation with the socioeconomic score [Spearman's Rho $=0.392, \mathrm{p}$ $<0.001]$, which also indicates that patients of higher socioeconomic status were prescribed drugs mainly from outside medical store considering that they will be able to afford such expenses on medicines. Thus, it seems that the prescribing decision was significantly influenced by the capacity of the patients to purchase medicines from outside medical store.
In our study, we have considered only the cost of medications, whereas in practice other direct and indirect costs also play a significant role. Moreover, the drugs may go out of stock from the hospital pharmacy on a number of occasions, which further increase the economic burden on the patients. We have not considered whether the drug is actually dispensed or not from the hospital pharmacy while calculating the cost of the prescription. These are the limitations of our study.

\section{CONCLUSION}

Hospitals should keep most of the prescribed drugs in their pharmacies in order to reduce the cost burden on the patients. Further, it seems that the prescribing decision in psychiatry outpatient department in our tertiary care hospital was significantly influenced by the socioeconomic status of the patient.

\section{ACKNOWLEDGEMENTS}

We thank Dr. S. R. Parkar, Professor \& Head, Dept of Psychiatry, Seth GS Medical College \& KEM Hospital, Mumbai.

\section{Funding: No funding sources \\ Conflict of interest: None declared \\ Ethical approval: The study was approved by the Institutional Ethics Committee}

\section{REFERENCES}

1. World Health Organization: The World Health Report 2001: Mental health - new understanding, new hope Geneva: WHO. 2001.

2. Ilyas S, Moncrieff J. Trends in prescriptions and costs of drugs for mental disorders in England, 1998-2010. Br J Psychiatry. 2012;200(5):393-8.

3. Exeter D, Robinson E, Wheeler A. Antidepressant dispensing trends in New Zealand between 2004 and 2007. Aust N Z J Psychiatry. 2009;43(12):1131-40.

4. Olfson M, Marcus SC. National patterns in antidepressant medication treatment. Arch Gen Psychiatry. 2009;66(8):848-56.

5. Chong MY, Tan CH, Fujii S, Yang SY, Ungvari GS, $\mathrm{Si} \mathrm{T}$, et al. Antipsychotic drug prescription for schizophrenia in East Asia: rationale for change. Psychiatry Clin Neurosci. 2004;58(1):61-7.

6. WHO International Working Group for Drug Statistics Methodology, WHO Collaborating Centre for Drug Statistics Methodology, WHO Collaborating Centre for Drug Utilization Research and Clinical Pharmacology. Introduction to Drug Utilization Research. Geneva: World Health Organization. 2003.

7. Grover S, Avasthi A. Antipsychotic prescription pattern: A preliminary survey of Psychiatrists in India. Indian J Psychiatry. 2010;52(3):257-9.

8. Grover S, Avasth A, Kalita K, Dalal PK, Rao GP, Chadda RK, et al. IPS multicentric study: 
Antidepressant prescription patterns. Indian J Psychiatry. 2013;55(1):41-5.

9. Trivedi JK, Dhyani M, Yadav VS, Rai SB. Antipsychotic drug prescription pattern for schizophrenia: Observation from a general hospital psychiatry unit. Indian J Psychiatry. 2010;52(3):279.

10. Thakkar KB, Jain MM, Billa G, Joshi A, Khobragade AA. A drug utilization study of psychotropic drugs prescribed in the psychiatry outpatient department of a tertiary care hospital. J Clin Diagn Res. 2013;7(12):2759-64.

11. Sarkar P, Chakraborty K, Misra A, Shukla R, Swain SP. Pattern of psychotropic prescription in a tertiary care center: a critical analysis. Indian J Pharmacol. 2013;45(3):270-3.

12. American Psychiatric Association. Diagnostic and Statistical Manual of Mental Disorders, Fourth Edition, Text Revision. Washington, DC: American Psychiatric press. 2000.

13. Kumar N, Shekhar C, Kumar P, Kundu AS. Kuppuswamy's socioeconomic status scale updating for 2007. Indian J Pediatr. 2007;74(12):1131-2.

14. Cramer JA, Rosenheck R. Compliance with medication regimens for mental and physical disorders. Psychiatr Serv. 1998;49(2):196-201.
15. Osterberg L, Blaschke T. Adherence to medication. N Engl J Med. 2005;353(5):487-97.

16. Mitchell AJ, Selmes T. Why don't patients take their medicine? Reasons and solutions in psychiatry. Advances in Psychiatric Treatment. 2007;13(5):33646.

17. Thieda P, Beard S, Richter A, Kane J. An economic review of compliance with medication therapy in the treatment of schizophrenia. Psychiatr Serv. 2003;54(4):508-16.

18. Sharma P, Das SK, Deshpande SN. An estimate of the monthly cost of two major mental disorders in an Indian metropolis. Indian $\mathrm{J}$ Psychiatry. 2006;48(3):143-8.

19. Gupta N, Sharma D, Garg SK, Bhargava VK. Auditing of Prescriptions to study utilization of antimicrobials in a tertiary hospital. Indian Journal of Pharmacology. 1997;29(6):411-5.

Cite this article as: Goyal SG, Kurle DG, Samant BD. Observational study to assess prescription cost and its relation to the socioeconomic status of the patients in psychiatry outpatient department in a tertiary care hospital. Int J Basic Clin Pharmacol 2016;5:307-11. 